\title{
BMJ Open The Environmental footprint of morphine: a life cycle assessment from opium poppy farming to the packaged drug
}

\author{
Scott McAlister, ${ }^{1}$ Yanjun Ou, ${ }^{2}$ Elise Neff, ${ }^{3}$ Karen Hapgood, ${ }^{2}$ David Story, ${ }^{4}$ \\ Philip Mealey, ${ }^{5}$ Forbes McGain ${ }^{6}$
}

To cite: McAlister S, Ou Y, Neff $\mathrm{E}$, et al. The Environmental footprint of morphine: a life cycle assessment from opium poppy farming to the packaged drug. BMJ Open 2016;6: e013302. doi:10.1136/ bmjopen-2016-013302

- Prepublication history and additional material is available. To view please visit the journal (http://dx.doi.org/ 10.1136/bmjopen-2016013302).

Received 4 July 2016 Revised 21 September 2016 Accepted 29 September 2016

CrossMark

${ }^{1}$ Eco Quantum Life Cycle Consultants, Brunswick, Victoria, Australia ${ }^{2}$ Department of Chemical Engineering, Monash University, Clayton, Victoria, Australia

${ }^{3}$ Sun Pharmaceuticals, Princes Highway, Port Fairy, Victoria, Australia

${ }^{4}$ University of Melbourne, Melbourne, Victoria, Australia ${ }^{5}$ Baxter Australia,

Toongabbie, Sydney, New South Wales, Australia ${ }^{6}$ Western Health, Footscray, Victoria, Australia

Correspondence to Dr Forbes McGain; forbes.mcgain@wh.org.au

\section{ABSTRACT}

Objective: To examine the environmental life cycle from poppy farming through to production of $100 \mathrm{mg}$ in $100 \mathrm{~mL}$ of intravenous morphine (standard infusion bag).

Design: 'Cradle-to-grave' process-based life cycle assessment (observational).

Settings: Australian opium poppy farms, and facilities for pelletising, manufacturing morphine, and sterilising and packaging bags of morphine.

Main outcome measures: The environmental effects (eg, $\mathrm{CO}_{2}$ equivalent (' $\mathrm{CO}_{2} \mathrm{e}$ ') emissions and water use) of producing $100 \mathrm{mg}$ of morphine. All aspects of morphine production from poppy farming, pelletising, bulk morphine manufacture through to final formulation. Industry-sourced and inventory-sourced databases were used for most inputs.

Results: Morphine sulfate $(100 \mathrm{mg}$ in $100 \mathrm{~mL})$ had a climate change effect of $204 \mathrm{~g} \mathrm{CO}_{2}$ e $(95 \% \mathrm{Cl} 189$ to $280 \mathrm{~g} \mathrm{CO}_{2} \mathrm{e}$ ), approximating the $\mathrm{CO}_{2}$ e emissions of driving an average car $1 \mathrm{~km}$. Water use was $7.8 \mathrm{~L}$ (95\% Cl 6.7- to $9.0 \mathrm{~L}$ ), primarily stemming from farming $(6.7 \mathrm{~L})$. All other environmental effects were minor and several orders of magnitude less than $\mathrm{CO}_{2}$ e emissions and water use. Almost $90 \%$ of $\mathrm{CO}_{2}$ e emissions occurred during the final stages of $100 \mathrm{mg}$ of morphine manufacture. Morphine's packaging contributed $95 \mathrm{~g} \mathrm{CO}_{2} \mathrm{e}$, which accounted for $46 \%$ of the total $\mathrm{CO}_{2}$ e $\left(95 \% \mathrm{Cl} 82\right.$ to $155 \mathrm{~g} \mathrm{CO}_{2}$ e). Mixing, filling and sterilisation of $100 \mathrm{mg}$ morphine bags added a further $86 \mathrm{~g} \mathrm{CO}_{2} \mathrm{e}$, which accounted for $42 \%\left(95 \% \mathrm{Cl} 80\right.$ to $92 \mathrm{~g} \mathrm{CO}_{2}$ e). Poppy farming $\left(6 \mathrm{~g} \mathrm{CO}_{2} \mathrm{e}, 3 \%\right.$ ), pelletising and manufacturing (18 $\mathrm{g} \mathrm{CO}_{2}$ e, $9 \%$ ) made smaller contributions to $\mathrm{CO}_{2}$ emissions.

Conclusions: The environmental effects of growing opium poppies and manufacturing bulk morphine were small. The final stages of morphine production, particularly sterilisation and packaging, contributed to almost $90 \%$ of morphine's carbon footprint. Focused measures to improve the energy efficiency and sources for drug sterilisation and packaging could be explored as these are relevant to all drugs. Comparisons of the environmental effects of the production of other drugs and between oral and intravenous preparations are required.

\section{Strengths and limitations of this study}

- The environmental footprint of individual identified drugs is unclear.

- We completed a life cycle assessment (LCA) of an identified drug that has worldwide use. The total environmental effects of producing $100 \mathrm{mg}$ of packaged morphine (for intravenous usage) were similar to or less than those of travelling $1 \mathrm{~km}$ in a standard car in all of the domains examined, including the carbon footprint, toxicity and water use. Nevertheless, when considering worldwide morphine usage, the environmental effects become significant.

- We found that the final stages of production formed $90 \%$ of morphine's carbon footprint, and packaging alone contributed almost $50 \%$. In contrast, poppy farming and manufacture of bulk morphine were minor contributors to morphine's $\mathrm{CO}_{2}$ e emissions.

- By quantifying morphine's carbon footprint and complementing this with a nation's (UK's) annual morphine usage, we approximated morphine's total carbon footprint.

- The main areas of uncertainty for our study relate to that for all LCAs, that is, reliance on industry data for inputs beyond what we obtained directly. Furthermore, we were unable to compare the environmental footprint of morphine in $10 \mathrm{mg}$ glass phials (another common preparation) as no companies were willing to make their data available to us.

\section{INTRODUCTION}

Healthcare's environmental effects are receiving increasing attention. ${ }^{12}$ Life cycle assessment (LCA) is a scientific method used to calculate the entire 'cradle-to-grave' environmental effects ('footprint') of a product or process. $^{3}$ LCA has been used to estimate healthcare's entire 'carbon footprint', which has been found to be responsible for $3 \%$ and $9.8 \%$ of the $2013 \mathrm{CO}_{2}$ equivalent (' $\mathrm{CO}_{2} \mathrm{e}$ ') emissions of England $^{4}$ and the $\mathrm{USA}^{5}$, 
respectively. The USA spends almost twice as much on healthcare $(17.1 \%)$ as a proportion of gross domestic product (GDP) as the UK (9.1\%). ${ }^{6}$ Australian healthcare $\mathrm{CO}_{2}$ e emissions are unknown, although healthcare costs are similar to those of the UK $(9.4 \%$ of GDP $){ }^{6}$ Furthermore, Australian clinical practice broadly reflects that in the UK, Europe and Canada, though it is less financially costly than healthcare in the USA. In 2012, the production of all pharmaceuticals used by the National Health Service (NHS) of England contributed $>20 \%$ of the total $\mathrm{CO}_{2}$ e emissions (ie, all purchasing, energy use and transport) arising from the NHS's activities. ${ }^{4}$ Owing to this environmental footprint, the UK NHS Sustainable Development Unit developed a guideline to perform pharmaceutical LCAs. ${ }^{7}$

LCAs exist for whole operations ${ }^{8-11}$ and individual devices, ${ }^{12-15}$ but LCAs of drugs are rarely publicly available $^{16}$ due primarily to the proprietary nature of drug synthesis. Some published 'in-house' (commercial in confidence) LCAs, however, have been performed by drug companies. ${ }^{17}$ Most published LCAs of pharmaceuticals examine only the technical aspects of drug manufacture. ${ }^{18-20}$ How drug ingredients are put together, however, is less clear, and industry LCA publications cannot be verified. A large majority of a drug's environmental effects are due to the manufacture of the actual drug that doctors prescribe, compared with the production of the precursor ingredients. ${ }^{21}$ It appears that the production of all drugs collectively has a very large carbon footprint, ${ }^{4}{ }^{5}$ although individual drug information is lacking. The primary aim of this study was, thus, to know further about the entire environmental effects of a drug as used by clinicians. We chose to study morphine as it was a commonly used drug, known worldwide, that Australia produced in considerable quantities, and that could be studied with the collaboration of supportive pharmaceutical companies.

Morphine is on the list of the WHO Essential Medicines $^{22}$ and "remains the most widely used opiate for the management of pain. ${ }^{23}$ In 2013, the global legal production of the three most common opiates in descending order were morphine 523 tonnes, codeine 361 tonnes and oxycodone 261 tonnes. ${ }^{24}$ There are four natural opiates derived from the opium poppy Papaver somniferum: morphine and codeine, as well as thebaine and oripavine (parent compounds to oxycodone and buprenorphine, respectively). ${ }^{25}$ Direct chemical synthesis of morphine has proved difficult, ${ }^{25}{ }^{26}$ and production via poppies remains the only commercial synthesis route. Australia produces $\sim 50 \%$ of the global supply of licit opium poppy alkaloids (plant-based nitrogencontaining organic compounds, such as morphine), including $37 \%$ of the licit morphine, exporting to Europe, the UK and elsewhere. ${ }^{24}$

We aimed to quantify all of morphine's environmental effects $\left(\mathrm{CO}_{2}\right.$ e emissions $=\mathrm{CO}_{2}$ eq, water use, aquatic and terrestrial pollution, etc), from opium poppy cultivation, production of morphine sulfate and through to intravenous formulation, including packaging. $\mathrm{Kg}$ $\mathrm{CO}_{2} \mathrm{eq}$ is the standard unit for measuring carbon footprints and expresses the global warming potential of different greenhouse gases in ' $\mathrm{CO}_{2} \mathrm{e}$ ' that would create the same amount of warming. ${ }^{27}$

Intravenous morphine in Australia is most commonly prepared in $10 \mathrm{mg}$ glass ampoules for bolus administration and as $100 \mathrm{mg}$ in $100 \mathrm{~mL}$ bags for infusions and patient-controlled analgesia. We were interested in the environmental effects of both intravenous preparations. We undertook a 'cradle-to-gate' LCA of morphine with GSK (Glaxo Smith Kline) and Baxter, both large, international pharmaceutical companies. Three companies in Australia produced $37 \%$ of the world's licit morphine, the majority of which $(>25 \%)$ was produced by GSK. ${ }^{28}$ Baxter did not manufacture morphine, but was the only company that packaged and sterilised the $100 \mathrm{mg}$ morphine into $100 \mathrm{~mL}$ bags in Australia. A cradle-to-gate LCA examines a product's life cycle from the beginning to its exit from the 'factory gate' and does not include the syringes, intravenous fluid-giving sets, etc, used by a clinician when administering the intravenous morphine to the patient. Sun Pharmaceutical Industries purchased GSK's opiate production business in 2015. Since all data were obtained from GSK, references are made to 'GSK' hereafter.

\section{METHODS}

Ethical approval for this LCA was granted by the Western Health Ethics Committee (QA 2014.10), Melbourne, Australia. The study was undertaken from April 2014 to April 2016. Funding was obtained from the Australian and New Zealand College of Anaesthetists and Monash University. Researchers had access to all data, which were obtained from (1) Tasmanian opium poppy farms and GSK's poppy pelletising facility, (2) GSK's opiate manufacturing facility in Victoria and (3) Baxter's intravenous manufacturing facility in Sydney. No patients were involved in this study. The research questions and outcome measures were developed entirely by the investigators.

LCA is a scientific method that provides environmental modelling of the entire life of a product or process. ${ }^{3}$ In 1991, The Society for Environmental Toxicology and Chemistry defined the six components to be analysed in an LCA: (1) raw material acquisition; (2) processing and manufacturing; (3) distribution and transportation; (4) use, reuse and maintenance; (5) recycling and (6) waste management. ${ }^{3} \quad$ The International Organization for Standardization (ISO) has standardised how LCAs should be performed (the ISO 14040 series). ${ }^{29}$ We performed a process-based LCA, that is, the environmental effect was calculated for each product or service in the life cycle based on measured inputs, such as electricity or chemical usage.

Following the ISO 14040 Standards, an LCA must have a System Boundary (figure 1), a clear a priori definition 
of what is and what is not to be included in the analysis. ${ }^{29}$ Following these standards,${ }^{29}$ all existent infrastructure required for morphine's production (such as plant equipment) lay external to the System Boundary. In contrast, anything that was used in the manufacture, transport or delivery of morphine was examined; that is, (1) raw material (plant-based products, eg, cellulose) extraction, (2) chemical reactions and solvents, (3) energy use, (4) transport of all these agents and (5) associated packaging and waste.

An LCA uses different types of data for modelling. Some data are directly collected, for example, the amount of electricity used by the morphinemanufacturing facility. Most LCA data, however, are not directly measured, but obtained from life cycle inventories calculated from many production sites as directly measuring all data would make most LCAs unviable. One example is all the inputs and outputs associated with the production of $1 \mathrm{kWh}$ of electricity from brown coal mining through to transmission. In this study, a hierarchy of data sources has been used in the following descending order: (1) data collected from poppy growers, GSK and Baxter Australia, (2) the Australian LCI database ${ }^{30}$ and (3) EcoInvent V3 (European data). ${ }^{31}$ Modelling was performed using the SimaPro 8 LCA software (PRé Consultants, Amersfoort, the Netherlands).

In process-based LCA, 'allocation' is required when a single process produces multiple outputs, so that environmental effects can be allocated to each output. ISO 14044 (4.3.4.2 Allocation procedure $)^{29}$ gives a stepwise process in dealing with multi-output processes: (1) avoid allocation through dividing processes, (2) allocate based

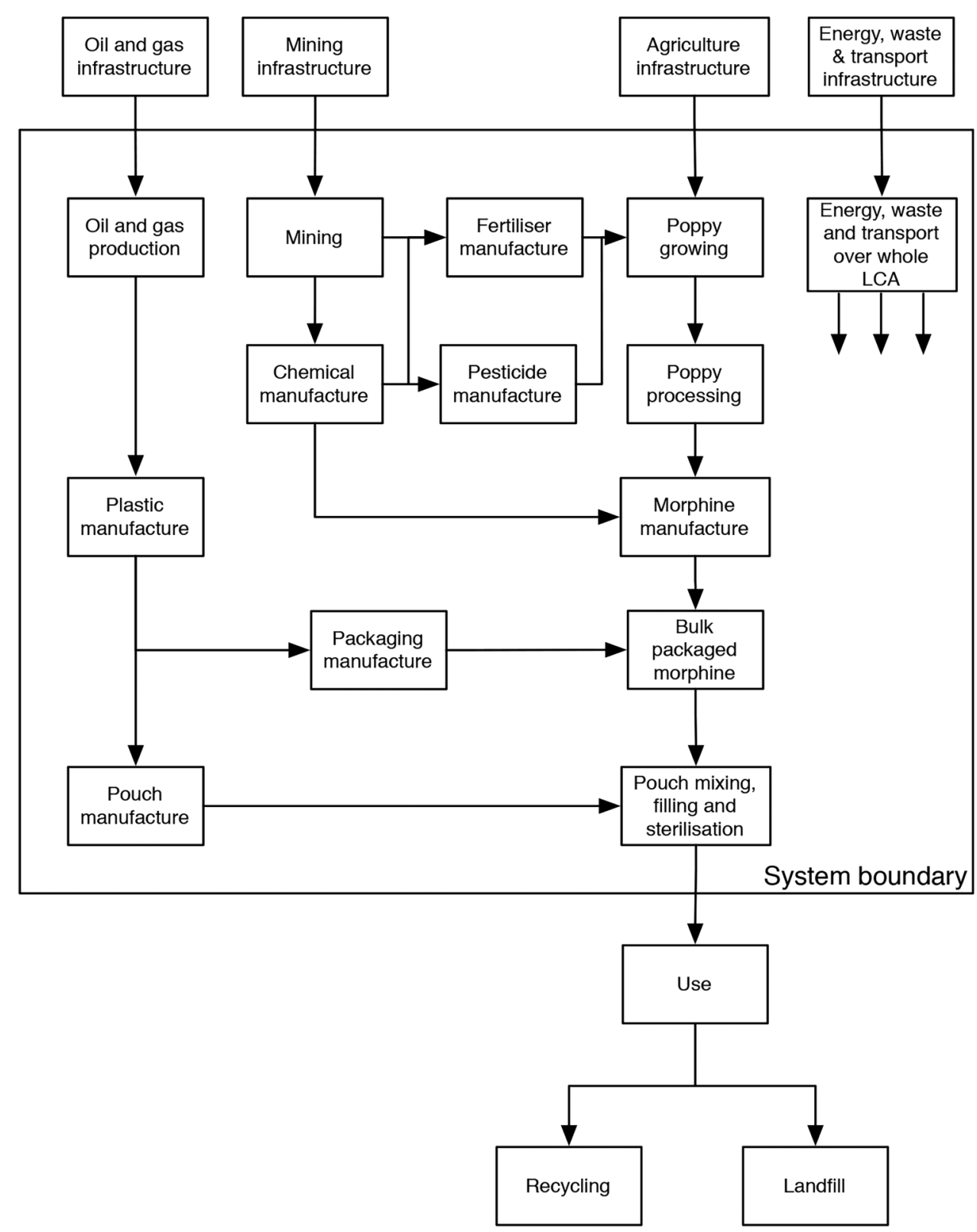

Figure 1 System Boundary for morphine production. LCA, life cycle assessment. 
on physical relationships such as mass or (3) allocate by other relationships, such as financial value.

There are two multi-output processes in morphine's manufacture by GSK: pelletising, which produces poppy straw pellets (for opiates) and poppy seeds (for food), and the concentrated poppy straw process, which produces morphine, codeine, oripavine and thebaine. We were unable to avoid allocation by dividing the processes (a single process provides poppy straw and seeds). Furthermore, a physical relationship (mass) did not capture the economic reality of why poppies were grown. Farmers grew poppies for the opioid content, not the poppy seeds-pharmaceutical companies were not about to grow opium poppies so that they could supply the food market. Therefore, we followed step 3 of ISO 14044 and allocated based on the financial value. ${ }^{29}$ The environmental effects were allocated based on the market value price (ie, price $/ \mathrm{kg}$ multiplied by $\mathrm{kg}$ mass) for each output. For each process, we calculated a weighted average based on annual production data from 2012 and 2013, and this was modelled in SimaPro.

All modelling included an uncertainty value expressed as a lognormal probability distribution derived from a qualitative scoring system (the Pedigree Matrix). ${ }^{32}$ Each input has uncertainty attributed to it from the qualitative scoring system derived from the data's reliability, completeness and temporal and geographical proximity, with these uncertainties being included in all major LCA databases. A final 95\% CI for a process is achieved based on the random sampling anywhere within the 95\% CIs for all inputs (Monte Carlo analysis). A Monte Carlo analysis by the LCA modelling software includes at least 1000 'runs' of random samples to reduce the chance of unusual results.

Impact assessment was performed using the ReCiPe LCIA (Life Cycle Impact Assessment) method. ${ }^{33}$ The following impact categories (and their units) were calculated: climate change $\left(\mathrm{g} \mathrm{CO}_{2} \mathrm{e}\right)$; ozone depletion $(\mathrm{kg}$ trichlorofluoromethane (CFC-11) equivalents); photochemical oxidant $(\mathrm{smog})$ formation ( $\mathrm{kg}$ non-methane volatile organic compound equivalents); and human, terrestrial and marine ecotoxicity ( $\mathrm{kg} \mathrm{1,4-dichlorobenzene}$ equivalents).

Normalisation is a method used to indicate the relative importance of an impact category; we 'normalised' the results for each impact category (ie, divided our results by an average Australian's per capita e emissions in each category) as per ISO $14044 .^{29}$ Normalisation takes into account potential effects from national electricity and fuel mixes. Per capita, Australia is a high emitter of $\mathrm{CO}_{2} \mathrm{eq}$, which may appear to reduce the environmental impacts of morphine production. Nevertheless, morphine made in the UK, for example, would have a lesser climate change impact $\left(\mathrm{CO}_{2} \mathrm{eq}\right)$ than that made in Australia due to the different electricity mix. A lesser environmental impact, being compared to a lesser per capita emission, may be comparable to the normalisation percentage of Australia.

\section{Farming, pelletising and transport}

Data for poppy cultivation and straw pelletising were collected from the GSK Head of Crop Supply. We obtained all data regarding opium poppy fertiliser, insecticides, herbicides, tractor diesel use and irrigation water use for a 2-year period (2012 and 2013). Road and domestic shipping of poppy straw and international shipping of chemicals to the farms were also examined.

\section{Bulk morphine manufacture}

Data from the manufacturing plant were obtained from several sources. Production of concentrated poppy straw (CPS) was a continuous process, but further manufacture of the final morphine sulfate was by a batch process. If a chemical was used only in the CPS process, then the 'Raw Material Spreadsheet' that records entire monthly chemical usage was used. If a chemical was used in other processes, then data from a system used to control and monitor process streams were used. Details of use/reuse of chemicals (including solvents) and water were obtained, including waste and sewage data.

For technical morphine (ie, 95\% morphine by dry weight) and morphine sulfate, exact chemical usage was obtained through individual batch sheets, with these recording all operating parameters, including input chemicals, and operating time and temperature. We randomly selected 30 batch sheets from each year of 2012 and 2013, and average values were calculated.

The GSK manufacturing facility monitored the electricity usage of individual equipment via an 'Energy Matrix' computer system. The final morphine production step, however, was not connected to the Energy Matrix. We, thus, calculated associated electricity use by multiplying the associated equipment's energy ratings with the respective operating times obtained from the batch sheets.

\section{Mixing, filling, sterilisation and packaging}

The Baxter Sydney factory did not manufacture morphine, but rather received bulk morphine sulfate, which was packaged as $100 \mathrm{mg}$ morphine into polyvinylchloride (PVC) plastic bags with $100 \mathrm{~mL}$ sterile $0.9 \%$ saline. In 2015, Baxter Australia sterilised 32 000 bags of morphine for intravenous use. Each PVC bag was packaged in high-density polyethylene (HDPE) plastic overpouch bags and cardboard boxes. Box 1 indicates the routine stages of production of morphine from these sources. We were unable to obtain data regarding the environmental effects of $10 \mathrm{mg}$ glass ampoules despite repeated requests to the manufacturers.

Baxter Australia purchased bulk morphine that did not require further chemical modification. Owing to contractual arrangements, the morphine received by Baxter Australia was not directly sourced from GSK. (GSK did supply Baxter with bulk morphine previously.) We had access to all aspects of the preparation of $100 \mathrm{mg}$ morphine in $100 \mathrm{~mL}$ bags by Baxter. Packaging for $100 \mathrm{mg}$ morphine required $16 \mathrm{~g}$ of $\mathrm{PVC}$ as the 
Box 1 Stages of morphine sulfate production in Australia (all directly examined in this life cycle)

Occurring in Tasmania

- Opium poppies grown in Tasmania, harvested and air-dried

- Dried poppy straw transported by road within Tasmania to be pellitised, and also for producing poppy seeds for the food industry

- Poppy pellets transported by ship to Melbourne, then by road to the manufacturing facility in Victoria

Occurring at GSK, Victoria

- To produce concentrated poppy straw with 70-80\% weight for weight purity, morphine, along with codeine, oripavine and thebaine, is extracted from the pellets in five stages:

- Aqueous extraction by filtration

- Solvent extraction

- Caustic extraction

- Precipitation by $\mathrm{pH}$ adjustment

- Separation

- Concentrated poppy straw is purified into technical morphine (ie, 95\% morphine by dry weight) through salt precipitation to eliminate soluble impurities prior to converting it back to morphine base

- Technical morphine is washed and filtered, resulting in dried cakes

- Sulfuric acid is added to produce morphine sulfate $(98 \%$ by dry weight)

- Morphine sulfate is crystallised, filtered, dried and milled

Occurring at Baxter, Sydney

- Bulk morphine sulfate obtained by Baxter, Sydney

- Morphine sulfate mixed with $0.9 \%$ saline, and packaged into polyvinylchloride plastic bags, pouches and cardboard boxes.

enclosing plastic bag, $9 \mathrm{~g}$ of HDPE plastic as the overwrapping pouch and a $9 \mathrm{~g}$ cardboard box (48 morphine bags per $440 \mathrm{~g}$ cardboard box).

The majority of Baxter's Sydney factory was devoted to the manufacture of intravenous fluids. We apportioned the relative amounts of mixing, filling, sterilisation and packaging required for morphine compared with other relevant factory production lines (eg, $0.9 \%$ saline $1 \mathrm{~L}$ bags) by comparing volumes of each production line over the year 2015. Mixing was the addition of bulk morphine to a heated, stirred salt solution $(0.9 \%$ saline) in large vats. Filling was the filling of PVC plastic bags with the aqueous solution, containing $100 \mathrm{mg}$ morphine. Sterilisation of these $100 \mathrm{mg}$ morphine bags occurred in large steam sterilisers. The majority of the energy for the Baxter's Sydney factory was produced on site by gas trigeneration (providing electricity, heating and cooling). A lesser amount of the factory's electricity was supplied from the New South Wales electricity grid (primarily sourced from black coal).

Packaging associated with a $\mathbf{1 0} \mathrm{mg}$ morphine glass ampoule We did not find a manufacturer willing to provide information regarding the manufacture of $10 \mathrm{mg}$ morphine glass ampoules. Nevertheless, we did weigh the packaging associated with such $10 \mathrm{mg}$ morphine ampoules at Footscray Hospital.

\section{RESULTS}

We completed a 'cradle-to-gate' LCA of morphine sulfate from opium poppy farming (fertilisers, insecticides and irrigation), poppy pelletisation, GSK's bulk morphine manufacture and Baxter's sterilisation and packaging. The environmental effects of producing $100 \mathrm{mg}$ of morphine were compared with a commonly identified activity (burning $1 \mathrm{~L}$ of petrol). For all but $\mathrm{CO}_{2}$ e emissions, ozone depletion and water use, burning $1 \mathrm{~L}$ of petrol had environmental effects which were several orders of magnitude greater than those of producing $100 \mathrm{mg}$ of morphine. We have focused on $\mathrm{CO}_{2}$ e emissions and provide further information regarding other environmental impacts in online supplementary table $\mathrm{S} 1$ with associated documentation. Only the details of $\mathrm{CO}_{2}$ e emissions are considered further.

The climate change effects of producing $100 \mathrm{mg}$ of morphine were $204 \mathrm{~g}$ of $\mathrm{CO}_{2}(95 \%$ CI 186 to $264 \mathrm{~g}$ of $\mathrm{CO}_{2}$ ). Figure 2 shows the breakdown in the effects of climate change $\left(\mathrm{CO}_{2}\right.$ e emissions) according to morphine's life cycle stages. Production of $100 \mathrm{mg}$ of bulk morphine (ie, from poppy farming and pelletising to GSK's bulk morphine) produced $24 \mathrm{~g}$ of $\mathrm{CO}_{2}(12 \%$ of the total), while filling, mixing, sterilisation and packaging produced $180 \mathrm{~g}$ of $\mathrm{CO}_{2}$ (88\% of the total). The average Australian is responsible for 18.3 tonnes of $\mathrm{CO}_{2}$ per annum, ${ }^{34}$ indicating that this $100 \mathrm{mg}$ of morphine producing $204 \mathrm{~g}$ of $\mathrm{CO}_{2}$ is $\sim 0.4 \%$ of the daily per capita

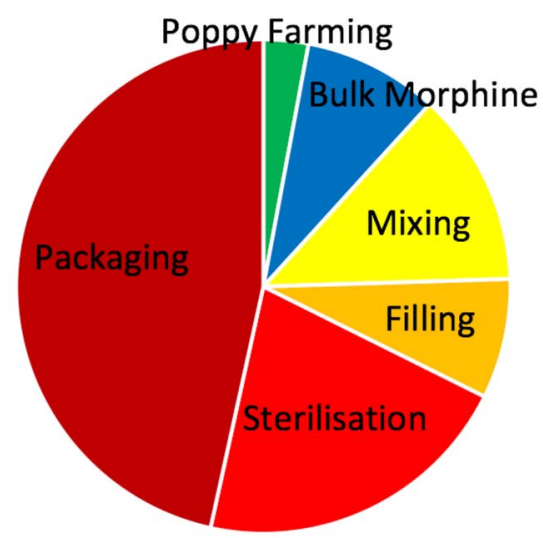

$$
\begin{array}{ll}
\text { - Poppy Farming (6g CO2, 3\%) } & \text { - Bulk Morphine (18g CO2, 9\%) } \\
=\text { Mixing }(26 \mathrm{~g} \mathrm{CO} 2,13 \%) & =\text { Filling (16g CO2, 8\%) } \\
\text { - Sterilisation (43g CO2, 21\%) } & \text { - Packaging (95g CO2, 46\%) }
\end{array}
$$

Figure 2 Greenhouse gas impacts ( $\mathrm{g} \mathrm{CO}_{2}$ and \%) by stage of morphine's life cycle (205 $\mathrm{g} \mathrm{CO}_{2}$ total). The individual listing of the final steps in the process of morphine production (mixing, filling, sterilising and packaging) indicates that they are the most important contributors to morphine $\mathrm{CO}_{2}$ emissions. 
Australian $\mathrm{CO}_{2}$ e emissions and equivalent to the $\mathrm{CO}_{2} \mathrm{e}$ emissions of driving an average car $\sim 1 \mathrm{~km} .{ }^{35}$

\section{Farming, pelletising and transport}

The entire contribution from poppy farming, pelletising and bulk morphine manufacturing was $24 \mathrm{~g}$ of $\mathrm{CO}_{2}$, which accounts for $12 \%$ of the total $\mathrm{CO}_{2}$ e $(95 \%$ CI 22 to $27 \mathrm{~g} \mathrm{CO}_{2} \mathrm{e}$ ). Poppy farming contributed $6 \mathrm{~g}$ of $\mathrm{CO}_{2}$, stemming particularly from nitrogen and phosphorus fertilisers $\left(3 \mathrm{~g}\right.$ of $\mathrm{CO}_{2}$ ) and farm machinery $(2 \mathrm{~g}$ of $\mathrm{CO}_{2}$ ). Diesel for farm machinery was much more important to $\mathrm{CO}_{2}$ e emissions than all other aspects of transport combined. Road, domestic shipping of poppy straw and international shipping of chemicals to the manufacturing facility contributed less than $0.2 \mathrm{~g}$ of $\mathrm{CO}_{2}$. Pelletising added only $0.5 \mathrm{~g}$ of $\mathrm{CO}_{2}$.

\section{Bulk morphine manufacture}

The GSK morphine-manufacturing plant added $18 \mathrm{~g}$ of $\mathrm{CO}_{2}$, arising mainly from the electricity $\left(9 \mathrm{~g}\right.$ of $\left.\mathrm{CO}_{2}\right)$ and chemicals (solvents, acids and alkalis and filter aids; $4 \mathrm{~g}$ of $\left.\mathrm{CO}_{2}\right)$ used. By process at the GSK factory, the $\mathrm{CO}_{2}$ e emissions from the production of concentrated poppy straw predominated $\left(10 \mathrm{~g}\right.$ of $\left.\mathrm{CO}_{2}\right)$, followed by morphine sulfate $\left(4 \mathrm{~g}\right.$ of $\mathrm{CO}_{2}$ ) and technical morphine (ie, $95 \%$ morphine by dry weight) production $\left(4 \mathrm{~g}\right.$ of $\left.\mathrm{CO}_{2}\right)$.

\section{Mixing, filling, sterilisation and packaging}

The final processes of morphine production (mixing, filling, sterilising and packaging) at Baxter's Sydney manufacturing plant contributed 181/205 $\mathrm{g} \mathrm{CO}_{2}(88 \%)$ to $100 \mathrm{mg}$ morphine's total $\mathrm{CO}_{2}$ footprint. Mixing (26 g of $\mathrm{CO}_{2}$ ), filling ( $16 \mathrm{~g}$ of $\mathrm{CO}_{2}$ ) and sterilisation ( $43 \mathrm{~g}$ of $\mathrm{CO}_{2}$ ) of $100 \mathrm{mg}$ of morphine bags added $85 \mathrm{~g}$ of $\mathrm{CO}_{2}$, which is $42 \%$ of the total $\mathrm{CO}_{2} \mathrm{e}(95 \%$ CI 80 to $92 \mathrm{~g}$ $\mathrm{CO}_{2} \mathrm{eq}$ ). Morphine's packaging contributed the largest amount to $\mathrm{CO}_{2}$ e emissions for any process, $95 \mathrm{~g}$ of $\mathrm{CO}_{2}$, which is $46 \%$ of the total $\left(95 \%\right.$ CI 82 to $\left.155 \mathrm{~g} \mathrm{CO}_{2} \mathrm{e}\right)$.

If Baxter's Sydney factory had used natural gas for heating/sterilising and the New South Wales' electricity grid for other energy requirements instead of gas trigeneration, the $\mathrm{CO}_{2}$ e emissions for a $100 \mathrm{mg}$ morphine pouch would have been $\sim 228 \mathrm{~g}$ of $\mathrm{CO}_{2}$. Packaging for $100 \mathrm{mg}$ morphine required $16 \mathrm{~g}$ of $\mathrm{PVC}$ as the enclosing plastic bag, a $9 \mathrm{~g}$ polyethylene overwrapping pouch and a 9 g cardboard box.

\section{Packaging associated with a $\mathbf{1 0} \mathrm{mg}$ morphine glass ampoule}

We estimated that the packaging masses associated with $10 \mathrm{mg}$ morphine ampoules were: one glass ampoule $(1.9 \mathrm{~g})$, one plastic polypropylene tray $(0.6 \mathrm{~g})$ and one cardboard and paper $(1.8 \mathrm{~g})$. In looking at the environmental effects of the packaging only, this contributed $6.9 \mathrm{~g}$ of $\mathrm{CO}_{2}$, that is, more than twice the $\mathrm{CO}_{2}$ e emissions of the $10 \mathrm{mg}$ bulk morphine (2.4 $\mathrm{g}$ of $\mathrm{CO}_{2}$ or $1 / 10$ th of $24 \mathrm{~g}$ of $\mathrm{CO}_{2}$ from $100 \mathrm{mg}$ of bulk morphine) itself.

\section{DISCUSSION}

We examined the environmental effects of producing morphine, from opium poppy cultivation through to the final packaged drug. The environmental effect of producing $100 \mathrm{mg}$ of morphine was $204 \mathrm{~g} \mathrm{CO}_{2}$ e for climate change. Other environmental effects examined were considerably smaller than burning $1 \mathrm{~L}$ of petrol for car transport, except for ozone depletion, though even this was just $0.04 \%$ of the ozone-depleting effects arising from an average Australian's daily activity (see online supplementary table S1). Importantly, almost $90 \%$ of morphine's carbon footprint arose from the final stages of production; steam sterilisation added $20 \%$ to the total, while packaging alone contributed almost half. The combined carbon footprint of poppy farming and bulk morphine manufacture was modest (12\%). Contrasting with prior studies of non-specific drug production, ${ }^{18}{ }^{36}$ chemicals (such as solvents, acids and alkalis) were not large contributors to morphine's $\mathrm{CO}_{2} \mathrm{e}$ emissions.

To give some perspective to our findings, the carbon footprint of the manufacture of $100 \mathrm{mg}$ of morphine $\left(204 \mathrm{~g}\right.$ of $\left.\mathrm{CO}_{2}\right)$ is similar to that of a single use plastic anaesthetic drug tray, ${ }^{14}$ or driving an average Australian car $1 \mathrm{~km} .{ }^{35}$ We deliberated what the wider environmental 'carbon impact' of a nation's morphine production would be, but caution that such considerations would likely be inaccurate due to the lack of robust data. The total UK requirements for morphine in 2015 were estimated to be $6498 \mathrm{~kg},{ }^{24}$ which (if entirely intravenous) would lead to 13250 tonnes of $\mathrm{CO}_{2}$ e emissions. While this is an overestimation (ie, less $\mathrm{CO}_{2}$ would be produced from oral morphine), the $\mathrm{CO}_{2}$ e emissions of intravenous morphine production would be equivalent to an annual usage of 4400 average Australian cars. ${ }^{35}$

The UK's Sustainable Development Unit found that $\sim 20 \%$ of the entire carbon footprint of the England's National Health Service was due to drug production and use. ${ }^{4}$ There are differences in the methods of inputoutput LCAs ${ }^{7}$ compared with our process-based LCA. Essentially, an input-output LCA is based on the financial transactions between sectors in the economy, calculating carbon and other environmental impacts for each sector, and associating this with their final financial value $\left(\mathrm{eg}, \mathrm{kgCO}_{2} / £\right)$. The purchase costs for morphine for the English NHS as a proportion of the total pharmaceutical purchases for England in 2014 were $£ 44$ million of $£ 8.9$ billion $^{37}$ (ie, $1 / 250$ th or $0.4 \%$ ).

No companies were willing to make their data available to us for morphine in $10 \mathrm{mg}$ glass phials. Belboom $e t a l^{8}$ studied the life cycle effects of injectable drug packaging only (not the drug itself), finding that a $1 \mathrm{~mL}$ glass phial filled with an unidentifiable sterile drug produced $65 \mathrm{~g}$ of $\mathrm{CO}_{2}$, and "the major source of energy consumption comes from cleaning the glass vial components." Using Belboom's study ${ }^{38}$ as a proxy for final formulation, if $10 \mathrm{mg}$ of our bulk morphine $(1 / 10$ th of $24 \mathrm{~g}$ $\left.\mathrm{CO}_{2}=2.4 \mathrm{~g} \mathrm{CO}_{2}\right)$ was filled in a glass phial, the related 
$\mathrm{CO}_{2}$ e emissions would be $65 \mathrm{~g}+2.4 \mathrm{~g}=67.4 \mathrm{~g} \mathrm{CO}_{2}$, with the phial and final formulation contributing $96 \%$, and the bulk morphine sulfate $4 \%$. Such results are in the same order of magnitude to our findings, but we caution close interpretation. Even if morphine's environmental footprint was exceptionally low compared to that of other pharmaceuticals, the final drug production stages and packaging are likely to have the largest environmental effects for most drugs.

Publically available studies of the life cycles of identifiable drugs are rare. A recent cradle-to-grave LCA of anaesthetic gases by Sherman et al. examined drugs using SciFinder ${ }^{39}$ (CAS web-based chemistry database, American Chemical Society, USA) as direct data were unavailable from the manufacturers. Drug synthesis pathways, however, change as the drug manufacturing process evolves from laboratory scale to full production, and the environmental effects can change considerably. ${ }^{21}$

Wernet et $a l^{21}$ studied the entire synthesis of a de-identified active pharmaceutical ingredient and found that its life cycle produced $68 \mathrm{~g}$ of $\mathrm{CO}_{2} / \mathrm{g}$ drug. Wernet's study did not include the final sterilisation processes nor packaging. Our study found that bulk morphine (ie, not including sterilisation and packaging) produced $240 \mathrm{~g}$ of $\mathrm{CO}_{2} / \mathrm{g}$ morphine, considerably more than Wernet's unidentified drug. We caution though that there may be considerable variation in processing between different drugs.

Our cradle-to-gate LCA of all processes required to produce intravenous morphine found that the $\mathrm{CO}_{2} / \mathrm{g}$ was $\sim 2040 \mathrm{~g}$ of $\mathrm{CO}_{2} / \mathrm{g}$ morphine. Although the ' $\mathrm{CO}_{2}$ intensity' of morphine is much greater (per gram) than for packaging, such packaging produces greater $\mathrm{CO}_{2} \mathrm{e}$ emissions due to the 100-fold greater masses involved. Our study adds weight to concerns that packaging may add greatly to the life cycle effects of many hospital products. ${ }^{40}$ We were unable to estimate the environmental effects of oral morphine tablets, though this is likely to be less than intravenous preparations due to the lesser disinfection needs, ${ }^{41}$ and reduced packaging requirements (we did not include the environmental effects of the plastic 'giving set/drip').

According to our study, it was challenging to identify rapid, inexpensive improvements in the environmental effects of production of morphine. Recently, GSK Victoria undertook extensive water and energy reduction programmes, saving 30 million litres of water annually through reuse, and reduced electricity consumption by $30 \%$. Furthermore, Baxter Sydney's factory already sourced its energy primarily from gas trigeneration, supplemented by the New South Wales electricity grid and a recently installed $500 \mathrm{~kW}$ solar photovoltaic system. Perhaps, we have underestimated the environmental effects of drug production since GSK and Baxter act with resource conservation in mind. Yet, even if Baxter Australia's energy source was natural gas and the New South Wales electricity grid, this would lessen $100 \mathrm{mg}$ of morphine's related $\mathrm{CO}_{2}$ e emissions by only $\sim 10-15 \%$. Yet, because of the importance of sterilisation and packaging, efforts to improve steriliser efficiencies and reducing/recycling cardboard/plastic packaging are worth exploring (eg, initiatives to recycle PVC plastic), ${ }^{42}$ particularly in the setting of carbon reduction targets.

We have shown from our study of $100 \mathrm{mg}$ of morphine in plastic bags that 'commercial in confidence' concerns by pharmaceutical companies to LCA can be solved through collaboration leading to robust, publicly available data. Nonetheless, we were unable to obtain data regarding $10 \mathrm{mg}$ of sterile morphine ampoules. As clinical end users of pharmaceuticals, it is incongruous that we are unable to obtain information regarding the environmental effects of drugs we are administering to patients, and concerted advocacy efforts by medical colleges and associations to ask for such information from pharmaceutical companies could assist further research.

The environmental footprint of a $100 \mathrm{mg}$ bag of morphine was small compared to many other processes and items used in hospitals, but nevertheless important when considering worldwide pharmaceutical use. Most (90\%) of morphine's carbon footprint arose from the latter stages of production, particularly packaging and sterilisation. The environmental effects of fentanyl (another widely used opiate) for comparison with those of morphine are required to begin to provide informed, 'environmentally aware' drug choices. The relative environmental footprints of oral versus intravenous pharmaceuticals also warrant attention. The environmental effects of drug distribution, storage, use by clinicians (including syringes) and hospital waste disposal also require exploration. The pharmaceutical industry could reduce its carbon footprint through greater energy efficiencies and use of renewables. Improved drug packaging and augmented recycling are also needed. Clinicians and government purchasing agencies could be empowered to have LCA data to choose drugs and other products based on their environmental footprint. ${ }^{1}{ }^{43}$

Acknowledgements The authors thank GSK and Baxter Australia for allowing access to their manufacturing site for data collection, Mark Rhodes of GSK UK for his expert advice and Simon Yoon and Bradley Keam of Baxter Australia for assistance in data collection. Tim Bowser (of SunPharma), Tom Penny (of ERM life cycle assessments) and Imogen Tennison (of the UK's Sustainable Development Unit) gave thoughtful comments. The authors also thank Assistant Professor Craig French for manuscript review.

Contributors FMG conceived the study, obtained funding, assisted in the methods and in obtaining results, wrote and revised the manuscript, and agrees to be accountable for all aspects of the work involved. SMA assisted in study design and was the primary author who developed the methods and obtained the results. SMA also cowrote the manuscript and revisions. YO obtained the data and assisted in drafting the work as well as approving the final manuscript version. EN assisted in grant funding, data acquisition, analysis and interpretation, as well as manuscript preparation and approval of the final manuscript. KH contributed to the conception of the work, and assisted in grant funding, design of the methods and manuscript preparation. PM assisted in obtaining data and analysis, revised the manuscript and approved the final manuscript version. DS assisted in grant funding submission, data analysis and interpretation of the work, revised the manuscript and approved the final manuscript version. 
Funding Financial support for this study was provided by Australian and New Zealand College of Anaesthetists (ANZCA) grant 2014.14 and additional support for YO's CHE4164 Integrated Industrial Project scholarship was provided by GSK Australia. A priori confidentiality agreements were signed between all authors and GSK, mandating that no precise details of any particular physical or chemical processes would be divulged in the public domain, and that GSK could not delay/prevent any manuscript submission beyond a reasonable timeframe. A similar informal agreement was also reached with Baxter, Australia, that would allow manuscript submission in a timely manner by the non-industry aligned authors. On 1 September 2015, GSK sold its opiate facilities in Australia to Sun Pharmaceutical Industries. Prior to this sale, GSK ceased production of morphine sulfate, but continues to manufacture less-refined technical morphine ( $95 \%$ pure by dry weight). We have kept the use of the term 'GSK' in this manuscript as they were the company involved in the study.

Competing interests FMG has received research grants and honorariums from ANZCA, SMA has received research grants and honorariums from ANZCA, YO has received research grants and honorariums from GSK Australia, EN worked for GSK Australia and now for SunPharma, KH has received research grants and honorariums from GSK Australia, DS has received research grants and honorariums from ANZCA and PM works for Baxter Australia.

Provenance and peer review Not commissioned; externally peer reviewed.

Data sharing statement Data will not be made available due to the confidential nature of the original source data (ie, the preparation of morphine).

Open Access This is an Open Access article distributed in accordance with the Creative Commons Attribution Non Commercial (CC BY-NC 4.0) license, which permits others to distribute, remix, adapt, build upon this work noncommercially, and license their derivative works on different terms, provided the original work is properly cited and the use is non-commercial. See: http:// creativecommons.org/licenses/by-nc/4.0/

\section{REFERENCES}

1. Pencheon D. Health services and climate change: what can be done? J Health Serv Res Policy 2009;14:2-4.

2. Ryan S, Sherman J. Sustainable anesthesia. Anesth Analg 2012;114:921-3.

3. Klöpffer W. The role of SETAC in the development of LCA. Int J Life Cycle Assess 2006;11:116-22.

4. Sustainable Development Unit. UK NHS. Carbon Footprint update for the NHS in England 2013. http://www.sduhealth.org.uk/policystrategy/reporting/nhs-carbon-footprint.aspx

5. Eckelman MJ, Sherman J. Environmental impacts of the US health care system and effects on public health. PLOS ONE 2016;11: e0157014.

6. World Bank. Health expenditure, total (\% of GDP) 2014. http://data worldbank.org/indicator/SH.XPD.TOTL.ZS

7. The Sustainable Development Unit UK. Greenhouse Gas Accounting Sector Guidance for Pharmaceutical Products and Medical Devices 2012 Nov. http://www.sduhealth.org.uk/areas-offocus/carbon-hotspots/pharmaceuticals.aspx

8. Morris DS, Wright T, Somner JE, et al. The carbon footprint of cataract surgery. Eye (Lond) 2013;27:495-501.

9. Campion N, Thiel CL, DeBlois J, et al. Life cycle assessment perspectives on delivering an infant in the US. Sci Total Environ 2012;425:191-8.

10. Thiel CL, Eckelman MJ, Guido R, et al. Environmental impacts of surgical procedures: life cycle assessment of hysterectomy in the US. Environ Sci Technol 2015;49:1779-86.

11. Woods DL, McAndrew T, Nevadunsky N, et al. Carbon footprint of robotically-assisted laparoscopy, laparoscopy and laparotomy: a comparison. Int J Med Robot 2015;11:406-12.

12. Dettenkofer M, Griesshammer R, Scherrer M, et al. Life-cycle assessment of single-use versus reusable surgical drapes (cellulose/polyethylene-mixed cotton system). Chirurg 1999; 70:485.

13. Ison E, Miller A. The use of LCA to introduce life-cycle thinking into decision-making for the purchase of medical devices in the NHS. $J$ Environ Assess Policy Manag 2000;2:453-76.
14. McGain F, McAlister S, McGavin A, et al. The financial and environmental costs of reusable and single-use plastic anaesthetic drug trays. Anaesth Intensive Care 2010;38:538-44

15. Eckelman M, Mosher M, Gonzalez A, et al. Comparative life cycle assessment of disposable and reusable laryngeal mask airways. Anesth Analg 2012;114:1067-72.

16. Sherman J, Le C, Lamers V, et al. Life cycle greenhouse gas emissions of anesthetic drugs. Anesth Analg 2012;114: 1086-90.

17. Jiménez-González C, Overcash MR. The evolution of life cycle assessment in pharmaceutical and chemical applications-a perspective. Green Chem 2014;16:3392-400.

18. Jiménez-González $C$, Curzons $A D$, Constable DJ, et al. Cradle-to-gate life cycle inventory and assessment of pharmaceutical compounds. Int J Life Cycle Assess 2004;9: 114-21.

19. Raymond MJ, Slater CS, Savelski MJ. LCA approach to the analysis of solvent waste issues in the pharmaceutical industry. Green Chem 2010;12:1826-34

20. De Soete W, Debaveye S, De Meester S, et al. Environmental sustainability assessments of pharmaceuticals: an emerging need for simplification in life cycle assessments. Environ Sci Technol 2014;48:12247-55.

21. Wernet G, Conradt S, Isenring HP, et al. Life cycle assessment of fine chemical production: a case study of pharmaceutical synthesis. Int J Life Cycle Assess 2010;15:294-303.

22. WHO. WHO Model List of Essential Medicines. 18th list (April 2013, Final Amendments- October 2013). 2013. http://apps.who.int/iris/ bitstream/10665/93142/1/EML 18 eng.pdf?ua=1

23. Australian and New Zealand College of Anaesthetists and Faculty of Pain Medicine. Acute pain management: scientific evidence. Australian Government, National Health and Medical Research Council, 2010

24. United Nations International Narcotics Control Board 2014. Narcotic Drugs. Estimated World Requirements for 2015, Statistics for 2013. http://www.incb.org/documents/Narcotic-Drugs/TechnicalPublications/2014/Narcotic Drugs Report 2014.pdf

25. Friderichs E, Christoph T, Buschmann H. Analgesics, centrally acting. Ullmann's encyclopedia of industrial chemistry. Wiley-VCH Verlag GmbH \& Co. KGaA, 2000.

26. Novak BH, Hudlicky T, Reed JW, et al. Morphine synthesis and biosynthesis-an update. Curr Org Chem 2000;4:343-62.

27. IPCC (Intergovernmental Panel on Climate Change). Climate change 2013: the physical science basis. In: Stocker TF, Qin D, Plattner G-K, et al., eds. Contribution of working group I to the fifth assessment report of the intergovernmental panel on climate change. Cambridge, UK and New York, NY, USA: Cambridge University Press, 2013:1535.

28. GSK Australia. GSK's parting gifts to local community 2015. http:// au.gsk.com/en-au/media/press-releases/2015/gsks-parting-giftsto-local-community/

29. The International Standards Organisation. ISO-14040. 2006. http:// www.iso.org/obp/ui/—iso:std:iso:14040:ed-2:v1:en

30. ALCAS. Australian Life Cycle Assessment Society. The Australian Life Cycle Inventory Database Initiative 2016. http://alcas.asn.au/ AusLCI/

31. Ecoinvent Centre. Ecoinvent-the world's most consistent and transparent life cycle inventory database. 2015. http://www. ecoinvent.ch/

32. Weidema BP. Multi-user test of the data quality matrix for product life cycle inventory data. Int J Life Cycle Assess 1998; 3:259-65.

33. Goedkoop M, Heijungs R, Huijbregts M, et al. ReCiPe 20082009. http://isites.harvard.edu/fs/docs/icb.topic1466993.files/Recipe Method.pdf

34. US Department of Energy. CDIAC, Carbon Dioxide Information Analysis Center, Carbon Dioxide Emissions by Country, Australia, 2016. http://cdiac.ornl.gov/

35. National Transport Commission Australia. Carbon Dioxide Emissions from New Australian Vehicles 2012. March 2013. http://www.ntc.gov. au/Media/Reports/(7D7B720E-DA94-7518-9F26-2B14367ED1C9). pdf

36. Henderson RK, Jiménez-González C, Constable DJ, et al. Expanding GSK's solvent selection guide-embedding sustainability into solvent selection starting at medicinal chemistry. Green Chem 2011;13:854-62.

37. Health and Social Care Information Centre. Prescription Cost Analysis, England-2014, Published 8 April 2015. http://www.hscic. gov.uk/catalogue/PUB17274

38. Belboom S, Renzoni R, Verjans B, et al. A life cycle assessment of injectable drug primary packaging: comparing the traditional 
process in glass vials with the closed vial technology (polymer vials). Int J Life Cycle Assess 2011;16:159-67.

39. American Chemical Society. Products. SciFinder. The choice for chemistry research. 2015. http://www.cas.org/products/scifinder

40. McGain F, Story D, Kayak E, et al. Workplace sustainability: the 'cradle to grave' view of what we do. Anesth Analg 2012;114:1134-9.

41. Medicines and Healthcare Products Regulatory Agency. British Pharmacopoeia. Appendix XVI D. Microbiological Quality of
Non-sterile Pharmaceutical Preparations and Substances for Pharmaceutical Use. 2016. https://www.pharmacopoeia.com/ reference-standards

42. The Vinyl Council of Australia. PVC Recovery in Hospitals, 2013. http://vinyl.org.au/about-pvc/pvc-products/pvc-in-healthcare/ pvc-recovery-in-hospitals

43. Schroeder K, Thompson T, Frith K, et al. Sustainable healthcare. Chichester, West Sussex, UK: Wiley, 2013. 